\title{
TECNOLOGIAS DIGITAIS DE INFORMAÇÃO E COMUNICAÇÃO: FERRAMENTAS PARA A IMPLEMENTAÇÃO E ARTICULAÇÃO DE UM PROJETO DE INICIAÇÃO CIENTÍFICA NA EDUCAÇÃO A DISTÂNCIA.
}

\author{
LONDRINA/PR MAIO/2018
}

\author{
Indiara Beltrame Brancher - UNOPAR - indiara.brancher@kroton.com.br \\ Leuter Duarte Cardoso Jr - UNOPAR - leuter.junior@kroton.com.br \\ Clévia Israel Faria França - UNOPAR - clevia.franca@kroton.com.br \\ Helenara Regina Sampaio Figueiredo - UNOPAR - helenara@kroton.com.br \\ Mariana da Silva Nogueira Ribeiro - UNOPAR - mariana.snogueira@kroton.com.br \\ Emerson Guzzi Zuan Esteves - UNOPAR - emerson.esteves@unopar.br \\ Vânia de Almeida Silva Machado - UNOPAR - vania.almeida@kroton.com.br
}

Tipo: Relato de Experiência Inovadora (EI)

Categoria: Métodos e Tecnologias

Setor Educacional: EDUCAÇÃO SUPERIOR

\section{RESUMO}

Este trabalho apresenta as ações para a implementação e articulação de um projeto de iniciação científica, voltado aos estudantes da Educação a Distância (EaD), mediado pelas Tecnologias Digitais de Informação e Comunicação (TDIC). Tal projeto tem como objetivo investigar práticas metodológicas utilizadas por professores da Educação Básica, em específico do Ensino Fundamental II, para o ensino de conceitos da Educação Financeira. O projeto conta com 241 alunos ativos na Plataforma de Iniciação Científica para a modalidade Educação a Distância, (PIC/EaD), oriundos das mais diversas regiões do país. Durante a análise da utilização da Ambiente Virtual (AVA) de Aprendizagem foi possível identificar que o processo de interação entre docentes e discentes ocorrem de forma síncrona e contínua, apresentando contribuições para melhoria das atividades desenvolvidas pelos pesquisadores.

Palavras-chave: Iniciação científica. Educação a Distância. Educação Financeira. Tecnologias Digitais de Informação e Comunicação.

\section{AGRADECIMENTOS}

KROTON, UNIVERSIDADE PITÁGORAS UNOPAR. 


\section{Introdução}

A iniciação científica (IC) é um conjunto de atividades que têm por finalidade a descoberta de novos conhecimentos no domínio científico e queum processo no qual a Universidade possibilita aos alunos um primeiro contato com os procedimentos, as técnicas e os métodos utilizados para o desenvolvimento da ciência. permite ao estudante de graduação desenvolver uma postura investigativa desde a formação inicial.

Busca despertar jovens talentos para a ciência, melhorar a empregabilidade, assim como o desenvolvimento de competências por meio da participação em projetos de pesquisa. Apesar do crescimento observado nas Trata-se de uma experiência pouco vivida na educação a distância até então, mas que por meio das TIC's, vem sendo possibilitada e ampliada nesta modalidade de ensino.

atividades de IC no Brasil, os estudos a respeito dessa desenvolvida na modalidade EaD ainda é incipiente (SUGUIMOTO et al, 2017).

Considerando esse cenário, os autores Suguimoto et al (2017) desenvolveram um estudo voltado a quais ferramentas devem ser utilizadas para viabilizar assim como, quais formas de motivar os alunos da IC na EaD. Os resultados do estudo, desenvolvido por esses pesquisadores, demonstraram que as ferramentas desenvolvidas por meio das TDIC possibilitam as discussões, debates e o acompanhamento da sequência de atividades atendendo as especificidades de cada projeto de pesquisa.

Levando em conta a relevância de pesquisas voltadas a viabilização da IC no EaD, esse Um trabalho desenvolvido por Suguimoto et al (2017), buscou explorar o assunto voltado à educação a distância, discutindo como fazer pesquisa e iniciação científica com alunos do $E A D$, quais ferramentas devem ser utilizadas e como motivar os alunos.

Os resultados demonstraram que as ferramentas desenvolvidas por meio das TIC's possibilitam discussões, debates e o acompanhamento da sequência de atividades que o projeto envolve, desde a elaboração de edital para inscrição e seleção de alunos da $\mathrm{EaD}$, treinamento em ambiente interativo em até três níveis, no qual ocorrem as atividades mediadas por meio de fórum, chat em tempo real, espaço para postagens de atividades e sistema de mensagens.

O presente artigo arelato busca apresentar as ações ações para a implementação e articulação de um projeto de iniciação científica, voltado aos estudantes da EaD, por meio das TDICpara a implementação de um projeto de Iniciação Científica por meio das 
TIC's, na modalidade de ensino à distância.

O projeto de IC aqui em pauta, tem como, com objetivo de investigar práticas metodológicas utilizadas por professores da Educação Básica, principalmente do Ensino Fundamental II, para o ensino de conceitos da Educação Financeira.

O tema Educação Financeira justifica-se devido ao fato de não serem raras as situações de adultos com dívidas ou pendências financeiras, sendo a Educação Básica fundamental para a orientação dos estudantes sobre como lidar de forma racional com seus recursos, compreendendo questões relacionadas a parcelamentos, juros e descontos. Sendo assim considera-se que a prática da Educação Financeira adotada nas escolas podem contribuir para a formação de um indivíduo com sensibilização maior acerca da estabilidade financeira.

Assim, esEstá em se projeto de pesquisa em andamento na Universidade Pitágoras Unopar na Modalidade de EaD, e busca compreender as metodologias utilizadas para o ensino da Educação Financeira na educação básica, e justifica-se a partir do momento em que busca despertar a reflexão sobre um processo educativo articulado e compromissado com o tema, esperando-se obter retornos sociais de médio e longo prazo.

Osenvolve estudantes dos cursos de graduação em envolvidos no projeto, a saber são: Ciências Econômicas, Gestão Financeira, Administração, Ciências Contábeis e Licenciatura em Matemática, uma vez que, esses cursos além de por possuir em suas ementas conteúdos relacionados a área de finanças, odevido a abordagem em suas grades curriculares por meio de disciplinas que contribuem com o debate em questão. Por tratar-se de um tema também é relevante, pois deve sque er abordado de forma transversal desde a Educação Básica. , diversas são as contribuições que os alunos das diferentes áreas de atuação citadas poderão oferecer.

Diante deste contexto, este relato visa apresentar como as TDIC têm oferecido ferramentas que possibilitem um desenvolvimento efetivo do projeto de IC na EaD. Para atingir o objetivo proposto apresentar-se-á na sequência a fundamentação teórica, metodologia, resultados e considerações finais sobre o tema.

\section{Fundamentação teórica}

No que é pertinente à EaD, as TDIC têm contribuído muito para propagação, desenvolvimento, reformulação e a disseminação dessa modalidade de ensino, 
possibilitando uma verdadeira revolução na EaD (VALENTE, 2014). Na perspectiva da construção do conhecimento, sabe-se que essa se dá por meio da cooperação que ocorre entre pessoas de um determinado grupo e essa interação acontece por meio das TDIC" (VALENTE, 2014, p. 145).

Para Costa, Duqueviz e Pedroza (2015) as TDIC podem e devem ser utilizadas em contexto escolar como instrumentos mediadores da aprendizagem de jovens que já as utilizam fora da escola, pois estamos inseridos num contexto contemporâneo que se ordena e atua ao redor das tecnologias digitais. De acordo com Sato e Tezani (2016) há ainda muitas dificuldades de inseri-las e explorar suas potencialidades pedagógicas no processo de ensino e aprendizagem e este é um dos desafios colocados à educação.

Valente (2014), apresenta que as TDIC passam a fazer parte das atividades de sala de aula e vem alterando a dinâmica da sala de aula, por exemplo, no que tange a organização dos tempos e espaços da escola, nas relações entre o aprendiz e a informação, no processo de interações entre alunos, e entre alunos e professor.

No que é pertinente a EaD, segundo Borba, Malheiros e Zulatto (2008) as TDIC podem propiciar interação e possibilidades de feedback rápido pela internet, em atividades síncronas e assíncronas, os autores enfatizam a necessidade de meios tecnológicos que viabilizem a comunicação, tais como os Ambientes Virtuais de Aprendizagem. Diante deste contexto, a EaD mediada por meio das TDIC permite que as diversas atividades educacionais possam ser construídas de forma colaborativa, ao mesmo tempo em que pode ser utilizada para potencializar e incentivar a prática da pesquisa nas suas diferentes searas.

No que se refere a pesquisa científica essa implica na aprendizagem assim como expressão desse saber construídos por meio de atividade de vivência cultural e prática. A IC tem por finalidade contribuir com a evolução da construção do conhecimento em diversas áreas, sendo planejada e executada a partir de critérios de processamento das informações. Para Silva (2016), "a pesquisa vem, deste modo, apoiar a perspectiva de aprendizagem, já que esta se resume na capacidade de fazer avançar o conhecimento científico e acadêmico, aprofundando o saber, possibilitando novas descobertas de maneira que elas proporcionem habilidades para saber planejar, ter pensamentos críticos, saber escrever, ter foco, entres tantas outras" (SILVA, 2016, p. 2).

Considerando que a pesquisa científica pode trazer contribuições para a formação do acadêmico e deve ser desenvolvida a partir de situações do cotidiano, acredita-se que, uma proposta de pesquisa sobre conteúdos da Educação Financeira possa trazer, além 
da prática, uma reflexão a respeito de como estes conteúdos estão sendo trabalhados na Educação Básica.

Os conteúdos relacionados a Educação Financeira estão muito presentes em nosso dia a dia, quer seja ao efetuar um financiamento, ou até mesmo, em situações mais simples como o desconto que recebemos ao fazermos uma compra com pagamento à vista, entre outros. De acordo com Miranda (2014) é necessário que as pessoas possuam conhecimentos matemáticos financeiros, pois isso tem reflexos diretos na inserção dos indivíduos na sociedade.

Rezende (2002), argumenta que o professor de matemática da Educação Básica deve ter uma maior atenção no preparo dos conteúdos relacionados a Educação Financeiro. Ou seja, os docentes, devem buscar fazer uso das melhores estratégias e metodologias de ensino, seleção adequadas das situações problemas de estudo, assim como primando por temas atuais, os quais despertem no aluno a necessidade de interpretar, exercitar, assim como buscar o conhecimento necessário para a solução das propostas/problemas financeiros apresentadas.

Logo, com intuito de investigar a respeito de quais práticas pedagógicas professores da Educação Básica estão utilizando para trabalhar conteúdos relacionados a Educação Financeira, está em andamento um projeto de IC na Universidade Pitágoras Unopar na Modalidade de $\mathrm{EaD}$, em que alunos interagem e colocam em prática a pesquisa acadêmica mediada pelas TDIC, em especial o AVA.

Diante disso, surgiu, por parte dos docentes que desenvolvem este projeto de IC, o interesse em identificar como se dá o processo de interação entre docentes e discentes por meio do estudo da ferramenta utilizada para esse fim. Apresentar-se-á na sequência a metodologia e os resultados e discussões emanados desse estudo.

\section{Metodologia}

Com o objetivo de investigar práticas metodológicas utilizadas por professores da Educação Básica para o ensino de conceitos da Educação Financeira foi proposto um projeto de iniciação científica nos cursos EaD. Conforme Battini, França e Reis (2017) a modalidade a distância se apresenta como um desafio a comunicação, sendo necessária, para viabilização da Iniciação Cientifica no EaD a utlização das tecnologias de informação e comunicação.

No caso do projeto de Educação Financeira foi adotado o AVA da instituição na qual o 
projeto está vinculado, como espaço de mediação, interação, participação e assim como de colaboração entre os participantes do projeto.

Suguimoto et al (2017) explicam que o AVA Stricto [1] é uma plataforma de formação, orientação e comunicação com os participantes dos projetos de pesquisa. Além disso, o AVA faz uso de ferramentas digitais de aprendizagem por meio de chat em tempo real, fóruns, assim com possibilita o acompanhamento permanente do andamento do projeto. $\mathrm{Na}$ sequência serão apresentados os resultados do uso das ferramentas digitais no desenvolvimento do projeto.

\section{Relato da PesquisaResultados e discussões}

O projeto de IC em Educação Financeira é um dos projetos que compõem a a Plataforma de Iniciação Científica para a modalidade EaD, denominado Programa de Iniciação Científica (PIC/EaD). O projeto foi elaborado atendendo as normativas Institucionais que regulamentam os processos de tramitação dos projetos de pesquisa na Universidade.

Suguimoto et al (2017, p. 4) explicam que o objetivo da IC na UNOPAR é promover a integração entre o ensino e a pesquisa. Senso que no programa de Pesquisa Insticuional "os alunos da graduação das modalidades de ensino presencial e a distância tem a oportunidade de participar da pesquisa científica, fortalecendo a sua formação". Os mesmos autores (SUGUIMOTO et al, 2017) destacam que Programa de Iniciação Científica no $\mathrm{EaD}$ - PIC/EaD é constituído de seis etapas que podem ser visualizadas na Figura 1.

Figura 1: Seis etapas do Programa de Iniciação Científica no EaD - PIC/EaD

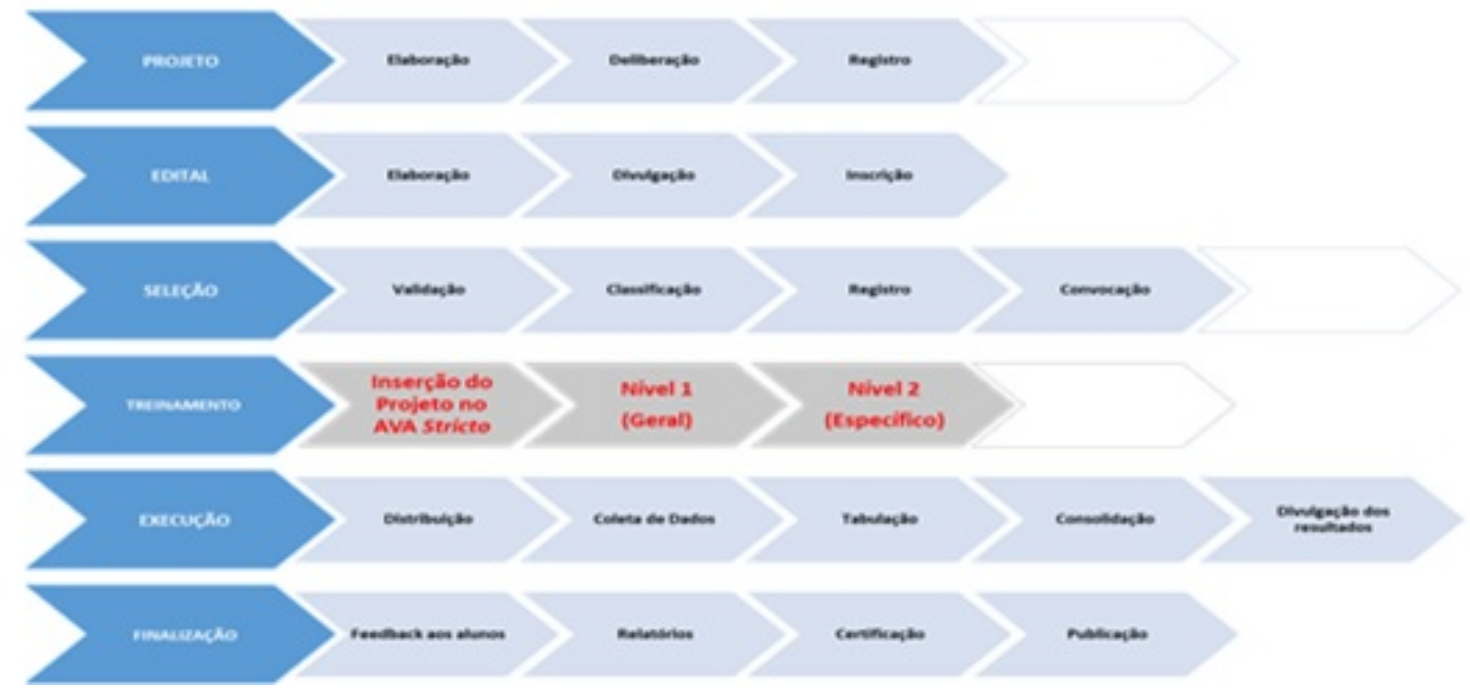


Fonte: Suguimoto et al (2017, p. 6)

Essa análise foca na fase de treinamento, pois é onde ocorre o processo de formação do aluno para o desenvolvimento da Iniciação Científica. Nessa estapa é onde ocorrem as discussões específicas de produção de conhecimento e elementos inerentes ao dia a dia do pesquisador (SUGUIMOTO et al, 2017) .

As atividades de treinamento acontecem em módulos de formação, a saber: treinamento Nível 1 (geral) e treinamento Nível 2 (específico). Conforme Battini, França e Reis (2017) o estudante de iniciação científica pode, por meio do AVA construir conhecimentos, por meio do desenvolvimetno de atividades, elaboração de questionamentos e participação em debates realizados, com o auxílio de chat semanal e fórum.

No que é pertinente as estratégias e ações para implementação das atividades iniciais, estiveram concentradas na capacitação dos estudantes no nível 1, denominado de nível geral. Atualmente a plataforma conta com 241 alunos ativos, sendo que cerca de $25 \%$ deles já realizaram esse treinamento.

Foram desenvolvidas as seguintes atividades: assistiram as Web aulas; participaram do fórum e fizeram a atividade avaliativa a respeito do Nível 1. Battini, França e Reis (2017) defendem que as propostas de IC para estudantes de graduação têm o objetivo de possibilitar aos mesmos o ingresso na pesquisa, potencializar o pensar criticamente, estimular a criatividade bem como contribuir para o desenvolvimento intelectual e humano.

Com relação as Web Aulas os estudantes assistiram: Web aula 1 - O que é iniciação científica; Web aula 2 - Currículo Lattes Página; Web aula 3 - Criando o Currículo Lattes Página; Web aula 4 - Caracterização das Bases e Banco de Dados; Web aula 5 Caracterização das Bases e Banco de Dados Página.

Os fóruns de discussão foram usados para o incentivo a discussão por meio da leitura de textos com as seguintes temáticas: Texto 1: Abordagem sobre os procedimentos para a realização de um projeto científico; Texto 2: Texto acerca da iniciação científica no Brasil. Com base nos materiais didáticos e nas Web aulas, presentes no AVA os estudantes responderam 10 questões que foram elaboradas pelos professores. As questões tinham como objetivo testar os conhecimentos adquiridos ao longo do treinamento nível 1.

A interação dos discentes por meio das TDIC, via AVA, é fundamental para que a 
disseminação do conhecimento ocorra, bem como para que a pesquisa possa ter um fluxo simétrico de informações entre docentes e discentes envolvidos com o projeto de pesquisa. O quadro 1 a seguir, apresenta-se comentários e dúvidas dos estudantes postados na ferramenta AVA.

Quadro 1: Exemplos de questionamentos postados pelos estudantes

\begin{tabular}{|c|c|}
\hline Tipo de Dúvida & Exemplos de dúvidas \\
\hline $\begin{array}{l}\text { Sobre as orientações para } \\
\text { cadastrar na Plataforma } \\
\text { Lattes }\end{array}$ & $\begin{array}{l}\text { "No início do nosso ambiente, há links que nos encaminham a } \\
\text { sites como o CNPq e a plataforma Brasil, devemos nos } \\
\text { cadastrar nestes ambientes? }\end{array}$ \\
\hline $\begin{array}{|lr|}\text { Comentários sobre } & \text { a } \\
\text { oportunidade } & \text { de } \\
\text { participação e expectativa }\end{array}$ & $\begin{array}{l}\text { "Ótimo começarmos as atividades tenho certeza que esse } \\
\text { projeto nos trará uma ótima oportunidade de agregar } \\
\text { conhecimentos". } \\
\text { "É um prazer fazer parte desse projeto de grande importância, } \\
\text { estou muito feliz por essa oportunidade". }\end{array}$ \\
\hline Sobre o AVA & $\begin{array}{l}\text { Boa tarde, temos um único fórum? Seria possível abrir outro } \\
\text { tópico para não misturar as questões? }\end{array}$ \\
\hline
\end{tabular}

Fonte: Da pesquisa (2018).

As dúvidas são sanadas pelos canais de comunicação e contatos são realizados visando a participação e permanência dos estudantes no projeto. Os 241 alunos ativos na Plataforma PIC/EAD estão espalhados por todas as regiões do Brasil, sendo que cerca de $30 \%$ são alunos da região Sudeste, $25 \%$ da região Nordeste, $23 \%$ da região Sul, $12 \%$ da região Centro-Oeste e $10 \%$ são residentes da região Norte do Brasil. Uma análise de tamanha profundidade, que pode reunir dados de todas as regiões de um país com tamanha extensão territorial, apenas se torna viável por meio do uso das Tecnologias de Informação e Comunicação e de ferramentas digitais.

Conforme Salvi (2017, p. 120) "os alunos participantes do projeto de Iniciação Científica EAD afirmaram que a experiência de pesquisa promoveu melhorias em seu desempenho acadêmico". Diante disso, os próximos passos da pesquisa envolverão a realização do treinamento nível 2 por parte dos alunos e os procedimentos e orientações necessárias, para que haja êxito na coleta de dados, que conduzam a resultados sólidos acerca do problema de pesquisa estudado. 


\section{Considerações finais}

Pode-se dizer que a presença das TDIC em nosso dia a dia tem alterado visivelmente os meios de comunicação e a forma como nos comunicamos. A realização de um projeto de pesquisa com alunos da modalidade a distância ainda é incipiente quantitativamente e é apenas possível pelo uso das tecnologias de informação e comunicação.

Estratégias de comunicação vêm sendo adotadas pelos professores envolvidos, para que os demais discentes possam realizar as atividades de pesquisa. Entre as novas estratégias discutidas, está um maior direcionamento das atividades para que se possa atingir os objetivos da pesquisa, sanando as dificuldades encontradas até o momento. $\mathrm{O}$ processo de interação entre docentes e discentes deverá ocorrer de forma síncrona e contínua, portanto, estratégias como chat em tempo real e fórum têm se intensificado.

Assim, pode-se observar ao longo do desenvolvimento do projeto, que ainda está em andamento, um aumento no interesse dos discentes para o debate sobre questões atuais que envolvem pesquisas científicas e Educação Financeira no campo acadêmico. As estratégias para formação de um discente pesquisador em ambiente virtual serão contínuas com vistas a promoção de uma qualificação educativa de todos membros do projeto.

\section{REFERÊNCIAS}

BATTINI, O.; FRANÇA, C. S.; REIS, S. R. dos. A formação inicial de professores e a iniciação científica na Modalidade a Distância: uma Experiência em Construção. EDUCERE XIII - Congresso Nacional de Educação. 2017. Disponível em: https://bit.ly/2lsR9pB. Acesso em: 05 abr. 2018.

BORBA, M. C.; MALHEIROS, A. P. S.; ZULATTO, R. B. A. Educação a Distância Online. Belo Horizonte: Autêntica, 2008.

COSTA, S. R. S.; DUQUEVIZ, B. C.; PEDROZA, R. L. S. Tecnologias Digitais como instrumentos mediadores da aprendizagem dos nativos digitais. Revista Quadrimestral da Associação Brasileira de Psicologia Escolar e Educacional, São Paulo, v.19, n.3, p.603-610, setembro/dezembro, 2015. Disponível em: https://bit.ly/2rO08Xn. Acesso: em 16 de mai. 2018.

MIRANDA, L. A. A importância da matemática financeira no cotidiano e na construção da cidadania. 2014. Paranavaí - PR. Disponível em: https://bit.ly/2wNtk6B. 
Acesso em: 17 de mai. 2018.

REZENDE, M. C. O pensar Matemático no ensino superior: concepções e estratégias de aprendizagem dos alunos. Tese de doutorado, Faculdade de Educação- Universidade Federal de Minas Gerais, 2002.

SATO, M. A. V.; TEZANI, T. C. R.. As tecnologias digitais da Informação e Comunicação na escola: alunos produtores de vídeos. Anais do SIED Simpósio Internacional de Educação a Distância 2016, São Carlos SP: Universidade Federal de São Carlos, 2016 v. 1, p. 1 - 14. Disponível em: https://bit.ly/2wOWiD9. Acesso em: 05 abr. 2018.

SILVA, M. F. A pesquisa na formação acadêmica: aprender a pesquisar fazendo pesquisa. 2016. Congresso Nacional de Educação. III Conedu.

SALVI, Vinícius Lopes. O Processo de iniciação científica mediado pelas tecnologias na Educação à Distância. Dissertação. Programa De Pós-Graduação Stricto Sensu Mestrado em Metodologias para o Ensino de Linguagens e suas Tecnologias. UNOPAR. 2017. 175 p. Disponível em: https://s3.amazonaws.com/pgsskrotondissertacoes/261280b3ef95bc8dbf994e84ff96f2ed.pdf Acesso em: 05 abr. 2018.

SUGUIMOTO, H.; JUNGBECK, M.; SILVA, S.; KLAUS, M.; SCARAMUZZA, B. PIC-EAD: Um Modelo de Iniciação Científica para o Ead. Congresso Internacional ABED de Educação a Distância. 2017. Disponível em: https://bit.ly/2rMLQXO. Acesso em: 05 abr. 2018.

VALENTE, J. A. A Comunicação e a Educação baseada no uso das Tecnologias Digitais de Informação e Comunicação. Revista UNIFESO - Humanas e Sociais. vol. 1, n. 1, 2014, pp. 141-166.

[1] (http://stricto.p gsskroton.com.br/) 